\title{
Pheochromocytoma presenting with severe hyperglycemia and metabolic acidosis following intra-articular glucocorticoid administration: a case report
}

\author{
Masako Tomoyasu*, Yusaku Mori, Ayako Fukase, Hideki Kushima and Tsutomu Hirano
}

\begin{abstract}
Background: There are several reports of pheochromocytoma crisis triggered by systemic glucocorticoid administration. However, pheochromocytoma crisis after intra-articular glucocorticoid administration has been rarely reported.

Case presentation: A 45-year-old Japanese man presented to our hospital with a sudden, severe headache. He had no history of diabetes. He had received an intra-articular injection of betamethasone ( $2 \mathrm{mg}$ ) for joint pain, 2 days prior to his admission. On examination, his blood pressure was $240 / 126 \mathrm{mmHg}$ and pulse was 120 beats/minute. The possibility of cerebrovascular events was ruled out by imaging studies and lumbar puncture. Blood tests revealed severe hyperglycemia $(523 \mathrm{mg} / \mathrm{dL}$ ) and metabolic acidosis ( $\mathrm{pH} 7.21$, anion gap $26.2 \mathrm{mEq} / \mathrm{L}$, lactate $11.75 \mathrm{mmol} / \mathrm{L}$ ) with a glycosylated hemoglobin level of 5.7\%. Although a urine sample could not be obtained, fulminant type 1 diabetes mellitus and diabetic ketoacidosis were suspected based on these findings. However, after the initial treatment for diabetic ketoacidosis, his insulin secretion was found to be normal and the plasma levels of ketones were not elevated. This excluded the possibility of fulminant type 1 diabetes mellitus and diabetic ketoacidosis. Subsequently, a left adrenal gland tumor and elevated levels of serum catecholamine and urinary catecholamine metabolites were detected, while his other hormone levels were normal. Serum catecholamine levels did not decrease following the clonidine test, and a functional scintigraphy using iodine-131 metaiodobenzylguanidine showed strong uptake in the region of the left adrenal gland. Although no signs of pheochromocytoma crisis, such as paroxysmal hyperglycemia and hypertension, had been observed since admission, a pheochromocytoma was diagnosed based on the investigations. After controlling his blood pressure, a left adrenalectomy was performed.
\end{abstract}

Conclusions: This case illustrates that intra-articular glucocorticoid administration can induce a pheochromocytoma crisis and an increase in hyperglycemia, and that pheochromocytoma crisis can resemble the clinical picture of fulminant type 1 diabetes mellitus owing to severe hyperglycemia with metabolic acidosis and normal glycosylated hemoglobin levels, especially under the influence of glucocorticoid.

Keywords: Diabetic ketoacidosis, Fulminant type 1 diabetes, Glucocorticoid, Hyperglycemia, Pheochromocytoma

\footnotetext{
* Correspondence: m-tomoyasu@med.showa-u.ac.jp

Division of Diabetes, Metabolism, and Endocrinology, Department of Internal

Medicine, Showa University School of Medicine, 1-5-8 Hatanodai, Shinagawa,

Tokyo 142-8555, Japan
}

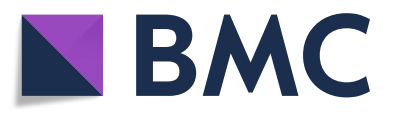

(c) The Author(s). 2019 Open Access This article is distributed under the terms of the Creative Commons Attribution 4.0 International License (http://creativecommons.org/licenses/by/4.0/), which permits unrestricted use, distribution, and reproduction in any medium, provided you give appropriate credit to the original author(s) and the source, provide a link to the Creative Commons license, and indicate if changes were made. The Creative Commons Public Domain Dedication waiver (http://creativecommons.org/publicdomain/zero/1.0/) applies to the data made available in this article, unless otherwise stated. 


\section{Background}

Pheochromocytoma is a catecholamine-secreting tumor that arises from the chromaffin cells of the adrenal medulla or from the paragangliomas of the extra-adrenal gland. One of the classical symptoms of pheochromocytoma crisis is hyperglycemia [1] that might be caused by increased insulin resistance in peripheral tissues and impaired insulin secretion [2]. However, the frequency of severe hyperglycemia (for example, plasma glucose levels $>400 \mathrm{mg} / \mathrm{dL}$ ) induced by pheochromocytoma crisis is largely unknown.

There are many reports of pheochromocytoma crisis triggered by systemic glucocorticoid administration [3]. Intra-articular glucocorticoid administration is a common practice for joint pains, and is considered much safer than systemic administration, which can lead to unfavorable metabolic changes including hyperglycemia.

We report a case of pheochromocytoma crisis following an intra-articular glucocorticoid injection. It was initially treated as diabetic ketoacidosis (DKA) induced by fulminant type 1 diabetes mellitus (FT1DM) due to the presence of severe hyperglycemia and metabolic acidosis with normal glycosylated hemoglobin (HbA1c) level.

\section{Case presentation}

A 45-year-old Japanese man received an intra-articular injection of glucocorticoid (betamethasone $2 \mathrm{mg}$ ) for pain in his right elbow joint 2 days prior to admission. On the day of admission, he experienced general fatigue. Two hours later, he experienced a sudden, severe headache and was brought to our emergency department in an ambulance.

He was diagnosed as having hypertension at 44 years of age, and his blood pressure was under control with lisinopril $10 \mathrm{mg} /$ day. He had no other significant past medical history or any episodic headaches. He was a tobacco smoker (20 cigarettes/day) for the past 24 years, and consumed approximately 50-100 g/day of alcohol, but was not addicted to any drugs, such as cocaine. He was married and had two children (a daughter, 12-years old; a son, 1-year old). His family had no history of diabetes, cancer, or any endocrine diseases, like pheochromocytoma, medullary thyroid carcinoma, parathyroid adenoma or hyperplasia, mucosal neuroma, and kidney cancer.

His vital signs were as follows: blood pressure, 240/126 $\mathrm{mmHg}$; pulse, 120 beats/minute (regular); temperature, $37.6^{\circ} \mathrm{C}$; respiratory rate, 25 breaths/minute. Except for excessive perspiration and sinus tachycardia, physical and neurological examinations showed no significant findings, such as pallor, tremor, enlarged thyroid gland or palpable thyroid nodule, enlarged lymph nodes, abnormal lung or heart sounds, meningeal irritation, and central or peripheral nerve dysfunction. Initially, subarachnoid hemorrhage was suspected due to severe headache and elevated blood pressure. However, computed tomography and magnetic resonance images of his head were normal. In addition, the cerebrospinal fluid drawn by lumbar puncture was clear, eliminating the possibility of cerebral vascular diseases, including subarachnoid hemorrhage. The results of the initial laboratory tests are shown in Table 1. Based on severe hyperglycemia and metabolic acidosis with normal HbA1c level on investigations, we suspected DKA caused by FT1DM.

We initiated the standard treatment for DKA, including intravenous insulin infusion and fluid replacement. The course of insulin infusion rates and plasma glucose levels is presented in Fig. 1. Following the initiation of insulin infusion, his plasma glucose level rapidly decreased and recovered to normal within 2 hours. In 18 hours, the lowest insulin infusion rate $(0.1 \mathrm{U} / \mathrm{h})$ was required to maintain normoglycemia. At the same time, our investigations showed that his basal insulin secretion was normal, and plasma ketone levels were not elevated, as shown in Table 1. These findings indicated metabolic acidosis induced by lactic acid, and excluded the possibility of FT1DM. Subsequently, he was screened for secondary diabetes. A left adrenal gland tumor $(3 \mathrm{~cm}$ in diameter) was detected by abdominal computed tomography (Fig. 2a). The levels of urinary catecholamine metabolites (metanephrine and normetanephrine) and serum catecholamines were significantly elevated; however, the other hormone levels were normal (Table 1). Elevated levels of serum adrenaline and noradrenaline did not reduce following the clonidine test, which indicated an autonomic catecholamine secretion. A functional scintigraphy of the adrenal gland using iodine-131 metaiodobenzylguanidine showed a strong uptake in the region of the left adrenal gland (Fig. 2b). These findings led to a diagnosis of pheochromocytoma. However, there were no findings suggestive of medullary thyroid carcinoma, parathyroid adenoma or hyperplasia, or any other endocrine diseases. His blood pressure was controlled with an $\alpha 1$ adrenergic receptor blocker doxazosin (12 mg/ day), following which a left adrenalectomy was performed 85 days after his admission. The tumor size was approximately $118.75 \mathrm{~cm}^{3}(9.5 \mathrm{~cm} \times 5 \mathrm{~cm} \times 2.5 \mathrm{~cm}$, Fig. 3a, b). On histopathological assessment, most tumor cells were positive for chromogranin A and synaptophysin, which were consistent with the diagnosis of pheochromocytoma (Fig. 3c-e) [4]. There were no signs of lymphovascular or capsular invasion. However, markers of malignancy, such as Ki-67 labeling index and Pheochromocytoma of the Adrenal Gland Scaled Score indicated borderline abnormalities (1.5\% and 4, respectively), which required careful follow-up $[5,6]$. Since this first event, he showed no signs of pheochromocytoma crisis such as paroxysmal hyperglycemia and hypertension. During the postoperative follow-up for 
Table 1 Laboratory data

\begin{tabular}{|c|c|}
\hline \multicolumn{2}{|l|}{ Blood tests at admission } \\
\hline \multicolumn{2}{|l|}{ Complete blood count } \\
\hline White blood cell & $19,600 / \mu \mathrm{L}$ \\
\hline Red blood cell & $509 \times 10^{4} / \mu \mathrm{L}$ \\
\hline Hemoglobin & $16.1 \mathrm{~g} / \mathrm{dL}$ \\
\hline Hematocrit & $47.30 \%$ \\
\hline Platelet & $12.9 \times 10^{4} / \mu \mathrm{L}$ \\
\hline \multicolumn{2}{|c|}{ Arterial blood gas (oxygen $6 \mathrm{l} /$ minute) } \\
\hline $\mathrm{pH}$ & 7.21 \\
\hline $\mathrm{PaCO}_{2}$ & $30.2 \mathrm{mmHg}$ \\
\hline $\mathrm{PaO}_{2}$ & $138.9 \mathrm{mmHg}$ \\
\hline Hydrogen carbonate & $11.8 \mathrm{mmoL} / \mathrm{L}$ \\
\hline Base excess & $-14.6 \mathrm{mmoL} / \mathrm{L}$ \\
\hline Lactate & $11.75 \mathrm{mmoL} / \mathrm{L}$ \\
\hline Anion gap & $26.2 \mathrm{mEq} / \mathrm{L}$ \\
\hline \multicolumn{2}{|c|}{ Additional tests for differential diagnosis } \\
\hline \multicolumn{2}{|l|}{ Blood test } \\
\hline Glucose & $109 \mathrm{mg} / \mathrm{dL}$ \\
\hline Insulin & $7.8 \mu \mathrm{U} / \mathrm{mL}$ \\
\hline C peptide & $2.64 \mathrm{ng} / \mathrm{mL}$ \\
\hline GAD antibody & $<0.5 \mathrm{U} / \mathrm{mL}$ \\
\hline $\mathrm{ACTH}$ & $23.1 \mathrm{pg} / \mathrm{mL}$ \\
\hline Cortisol & $14.6 \mu \mathrm{g} / \mathrm{dL}$ \\
\hline DHEA-S & $372 \mathrm{ng} / \mathrm{mL}$ \\
\hline Plasma renin activity & $6.1 \mathrm{ng} / \mathrm{mL} / \mathrm{hour}$ \\
\hline Aldosterone & $162.3 \mathrm{pg} / \mathrm{mL}$ \\
\hline Growth hormone & $0.10 \mathrm{ng} / \mathrm{mL}$ \\
\hline IGF-1 & $211 \mathrm{ng} / \mathrm{mL}$ \\
\hline TSH & $1.59 \mu \mathrm{lU} / \mathrm{mL}$ \\
\hline Free triiodothyronine & $2.63 \mathrm{pg} / \mathrm{mL}$ \\
\hline Free thyroxin & $0.93 \mathrm{ng} / \mathrm{dL}$ \\
\hline \multicolumn{2}{|l|}{ Biochemistry } \\
\hline Total bilirubin & $0.9 \mathrm{mg} / \mathrm{dL}$ \\
\hline Aspartate transaminase & $47 \mathrm{IU} / \mathrm{L}$ \\
\hline Alanine aminotransferase & $59 \mathrm{IU} / \mathrm{L}$ \\
\hline Creatine kinase & $215 \mathrm{IU} / \mathrm{L}$ \\
\hline Blood urea nitrogen & $16.9 \mathrm{mg} / \mathrm{dL}$ \\
\hline Creatinine & $1.35 \mathrm{mg} / \mathrm{dL}$ \\
\hline Sodium & $138.6 \mathrm{mEq} / \mathrm{L}$ \\
\hline Potassium & $3.1 \mathrm{mEq} / \mathrm{L}$ \\
\hline Chloride & $96.9 \mathrm{mEq} / \mathrm{L}$ \\
\hline Glucose & $523 \mathrm{mg} / \mathrm{dL}$ \\
\hline Hemoglobin A1c & $5.70 \%$ \\
\hline Total ketone body & $289 \mu \mathrm{moL} / \mathrm{L}$ \\
\hline Acetoacetic acid & $54 \mu \mathrm{moL} / \mathrm{L}$ \\
\hline
\end{tabular}

Table 1 Laboratory data (Continued)

$\begin{array}{ll}\text { 3-hydroxybutyric acid } & 235 \mu \mathrm{moL} / \mathrm{L} \\ \text { Urinary test } & 1.87 \mathrm{mg} / \text { day } \\ \text { Metanephrine } & 0.83 \mathrm{mg} / \text { day } \\ \text { Normetanephrine } & 322.4 \mu \mathrm{g} / \mathrm{day} \\ \text { Adrenalin } & 347.6 \mu \mathrm{g} / \mathrm{day} \\ \text { Noradrenaline } & 1003.9 \mu \mathrm{g} / \mathrm{day} \\ \text { Dopamine } & \\ \text { Clonidine (0.15 mg) suppression test } & \\ \text { Baseline } & 0.15 \mathrm{ng} / \mathrm{mL} \\ \text { Adrenaline } & 0.31 \mathrm{ng} / \mathrm{mL} \\ \text { Noradrenaline } & \leqq 0.01 \mathrm{ng} / \mathrm{mL} \\ \text { Dopamine } & \\ 3 \text { hours after clonidine } & 0.11 \mathrm{ng} / \mathrm{mL} \\ \text { Adrenaline } & 0.27 \mathrm{ng} / \mathrm{mL} \\ \text { Noradrenaline } & \leqq 0.01 \mathrm{ng} / \mathrm{mL} \\ \text { Dopamine } & \end{array}$

ACTH adrenocorticotropic hormone, DHEA-S dehydroepiandrosterone sulfate, GAD glutamic acid decarboxylase, IGF-1 insulin-like growth factors-1, $\mathrm{PaCO}_{2}$ partial pressure of arterial carbon dioxide, $\mathrm{PaO}_{2}$ partial pressure of arterial oxygen, $\mathrm{TSH}$ thyroid-stimulating hormone

28 months, he did not show any symptoms or signs indicating recurrence of pheochromocytoma.

\section{Discussion}

We encountered a case of pheochromocytoma crisis, which was possibly triggered by an intra-articular administration of glucocorticoid, 2 days prior to the crisis. Furthermore, it might have contributed to the development of severe hyperglycemia during the pheochromocytoma crisis. Accompanied by metabolic acidosis and normal HbA1c levels, the severe hyperglycemia misled us to a diagnosis of DKA induced by FT1DM.

One case of pheochromocytoma crisis induced by intra-articular glucocorticoid injection has been reported in the literature [7], in which the pheochromocytoma crisis developed 1 day after an injection of dexamethasone into the shoulder joint (the dose is not mentioned). In our case, the pheochromocytoma crisis developed 2 days after a dexamethasone injection into the elbow joint. A previous study demonstrated the kinetics of glucocorticoid delivered through an intra-articular injection [8]. In patients who received a dose of methylprednisolone acetate $40 \mathrm{mg}$, serum levels of methylprednisolone were still elevated 3 days after the intra-articular injections. Thus, it is reasonable to assume that the intra-articular glucocorticoid injection triggered the pheochromocytoma crisis in this case.

In the pheochromocytoma crisis in our case, severe hyperglycemia with metabolic acidosis and normal 


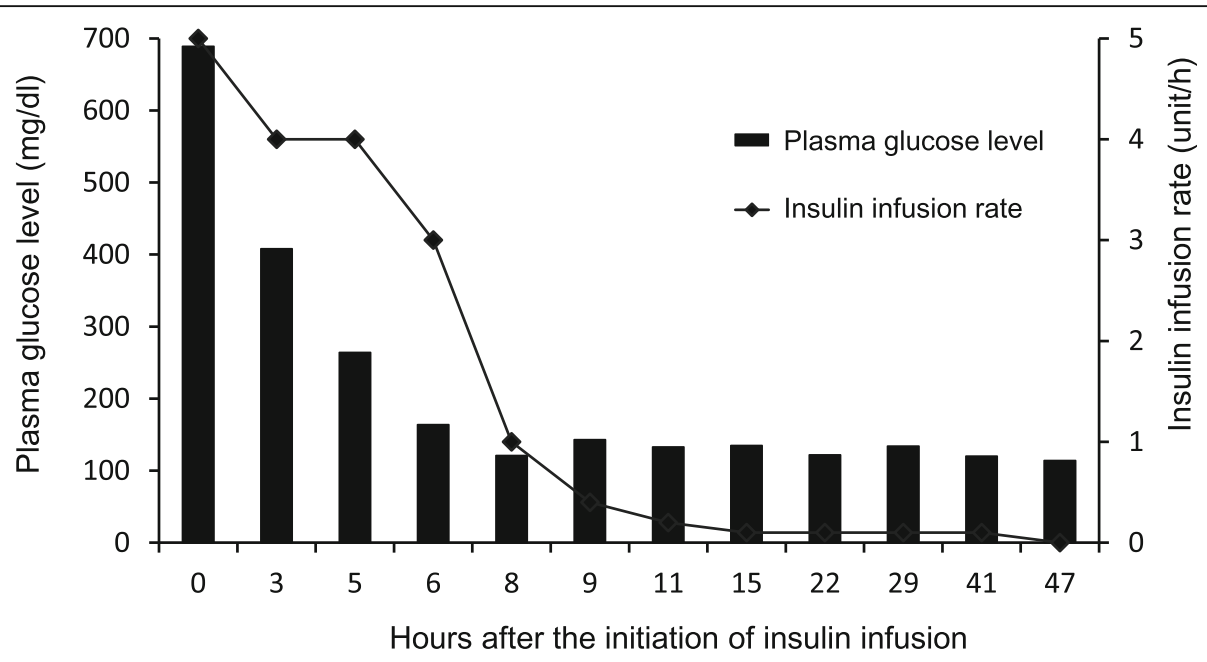

Fig. 1 Course of plasma glucose levels and insulin infusion rate. Bars show plasma glucose levels and the line indicates insulin injection rate at indicated hours after the treatment

HbA1c levels were observed, due to which we initially suspected DKA induced by FT1DM. FT1DM, a subtype of T1DM, is characterized by an extremely rapid process of $\beta$-cell destruction [9]. In most cases of FT1DM, HbA1c levels are normal during DKA. In our patient, who had no history of diabetes, the intra-articular glucocorticoid injection probably enhanced the hyperglycemia during the pheochromocytoma crisis. Furthermore, metabolic acidosis induced by lactic acid has been reported in pheochromocytoma crisis [10]. When these changes occur simultaneously, the pheochromocytoma crisis can show findings similar to FT1DM-induced DKA. However, DKA induced by pheochromocytoma crisis has been rarely reported $[11,12]$. It is possible that this case would have developed DKA if insulin therapy had not been administered. DKA is a life-threatening condition; hence, the initial treatment should not be
A

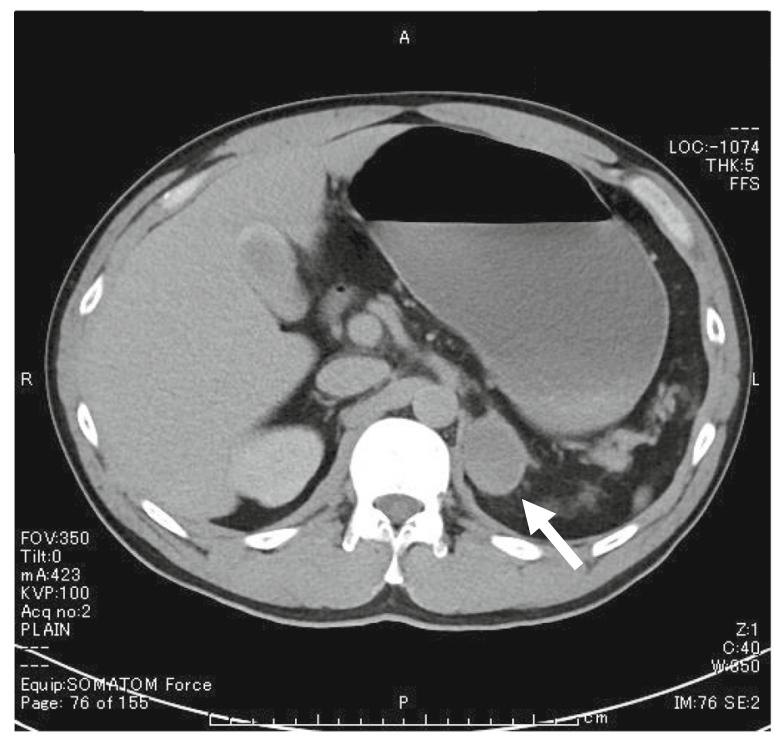

B
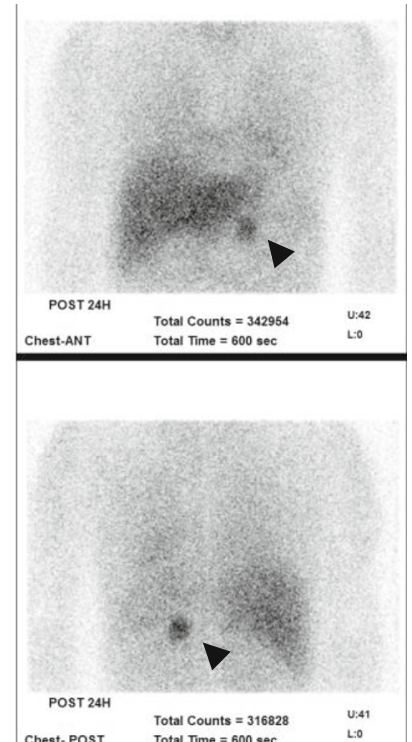

Fig. 2 Images of abdominal computed tomography and functional scintigraphy using iodine-131 metaiodobenzylguanidine. a Abdominal computed tomography, the arrow indicates a left adrenal gland tumor. b Anterior (upper) and posterior (lower) reprojected images of iodine-131 metaiodobenzylguanidine scintigraphy, the arrow head indicates strong uptake in the region of the left adrenal gland 

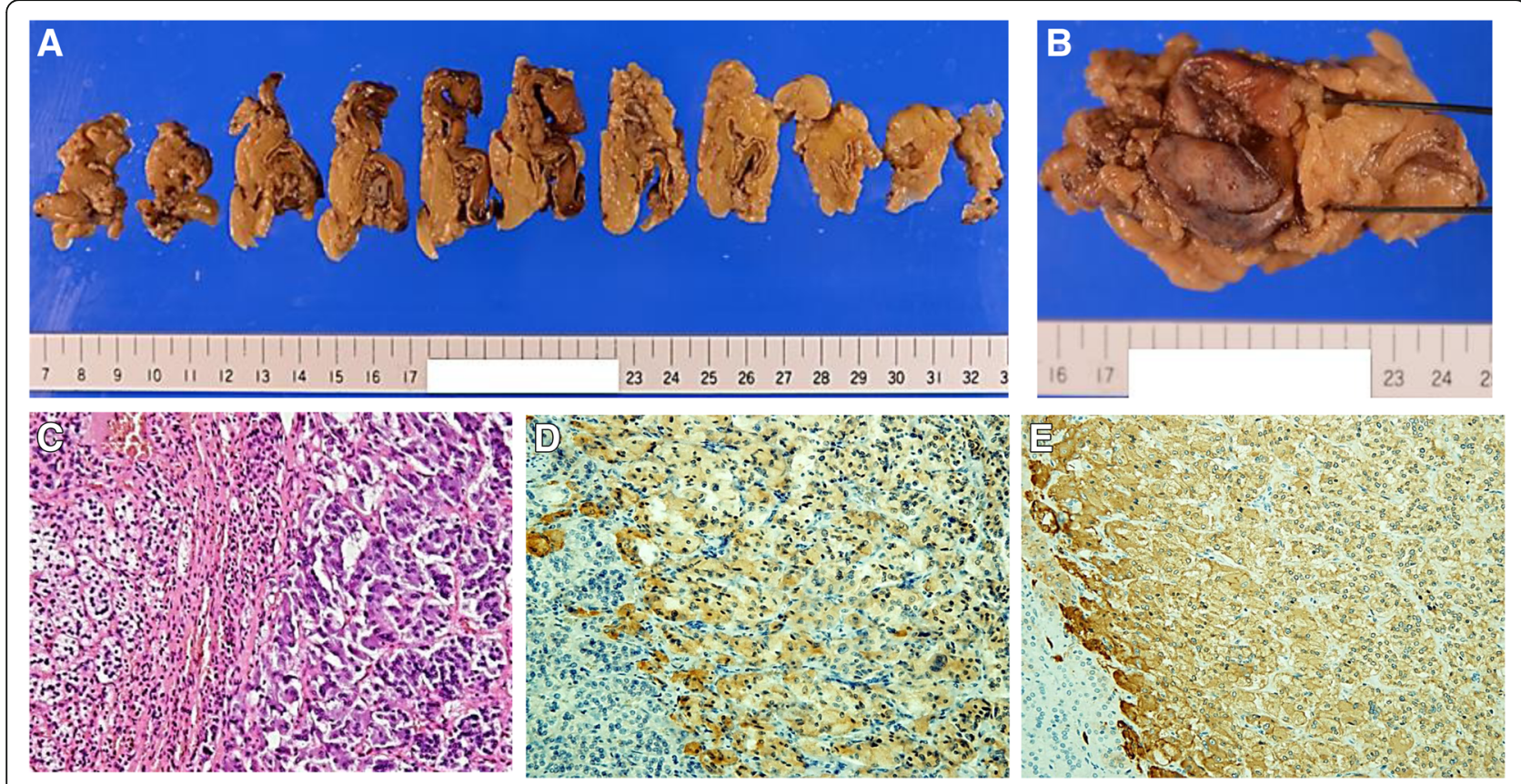

Fig. 3 A left adrenal gland tumor removed by adrenalectomy. a, b Gross pathology of the tumor of the left adrenal gland. c-e Microscopic image of the tumor under hhematoxylin and eosin staining (c), chromogranin A immunostaining (d), or synaptophysin immunostaining (e). The magnification was 200x. d, e The cells stained in brown are positive for chromogranin A and synaptophysin, respectively

delayed when suspected, especially when the differential diagnosis is uncertain.

\section{Conclusion}

There are two important lessons from this case. First, an intra-articular injection of glucocorticoid can be a possible cause of a pheochromocytoma crisis. Second, pheochromocytoma crisis occurring under the influence of glucocorticoid can have clinical findings similar to DKA induced by FT1DM.

\section{Abbreviations \\ DKA: Diabetic ketoacidosis; FT1DM: Fulminant type 1 diabetes mellitus; HbA1c: Glycosylated hemoglobin}

\section{Acknowledgements}

Not applicable.

\section{Funding}

There was no funding for this case report.

\section{Availability of data and materials}

The data that support the findings of this study are available from the corresponding author upon reasonable request.

\section{Authors' contributions}

MT treated this patient, and wrote and finalized the draft. YM supervised the treatment, and revised the manuscript. AF and HK treated this patient and contributed to the revision of the manuscript. TH supervised the treatment, and revised the manuscript. All authors read and approved the final manuscript.

Ethics approval and consent to participate Not applicable.

\section{Consent for publication}

Written informed consent was obtained from the patient for publication of this case report and any accompanying images. A copy of the written consent is available for review by the Editor-in-Chief of this journal.

\section{Competing interests}

The authors declare that they have no competing interests.

\section{Publisher's Note}

Springer Nature remains neutral with regard to jurisdictional claims in published maps and institutional affiliations.

Received: 24 July 2018 Accepted: 6 December 2018 Published online: 05 January 2019

\section{References}

1. Turnbull DM, Johnston DG, Alberti KG, Hall R. Hormonal and metabolic studies in a patient with pheochromocytoma. J Clin Endocrinol Metab. 1980:51:930-3.

2. La Batide-Alanore A, Chatellier G, Plouin P. Diabetes as a marker of pheochromocytoma in hypertensive patients. J Hypertens. 2003;21:1703-7.

3. Rosas AL, Kasperlik-Zaluska AA, Papierska L, Bass BL, Pacak K, Eisenhofer G. Pheochromocytoma crisis induced by glucocorticoids: a report of four cases and review of the literature. Eur J Endocrinol. 2008;158:423-9.

4. Białas M, Okoń K, Dyduch G, Ciesielska-Milian K, Buziak M, HubalewskaDydejczyk A, et al. Neuroendocrine markers and sustentacular cell count in benign and malignant pheochromocytomas - a comparative study. Pol J Pathol. 2013;64:129-35.

5. Thompson LD. Pheochromocytoma of the Adrenal gland Scaled Score (PASS) to separate benign from malignant neoplasms: a clinicopathologic and immunophenotypic study of 100 cases. Am J Surg Pathol. 2002;26: $551-66$

6. Nagura S, Katoh R, Kawaoi A, Kobayashi M, Obara T, Omata K. Immunohistochemical estimations of growth activity to predict biological behavior of pheochromocytomas. Mod Pathol. 1999;26:1107-11.

7. Takagi S, Miyazaki S, Fujii T, Daikoku S, Sutani Y, Morii I, et al. Dexamethasone-induced cardiogenic shock rescued by percutaneous 
cardiopulmonary support (PCPS) in a patient with pheochromocytoma. Jpn Circ J. 2000;64:785-8.

8. Armstrong RD, English J, Gibson T, Chakraborty J, Marks V. Serum methylprednisolone levels following intra-articular injection of methylprednisolone acetate. Ann Rheum Dis. 1981;40:571-4.

9. Imagawa A, Hanafusa T, Uchigata Y, Kanatsuka A, Kawasaki E, Kobayashi T, et al. Fulminant type 1 diabetes: a nationwide survey in Japan. Diabetes Care. 2003:8:2345-52.

10. Bornemann M, Hill SC, Kidd GS 2nd. Lactic acidosis in pheochromocytoma. Ann Intern Med. 1986;105:880-2.

11. Edelman ER, Stuenkel CA, Rutherford JD, Williams GH. Diabetic ketoacidosis associated with pheochromocytoma. Cleve Clin J Med. 1992;59:423-7.

12. Isotani H, Fujimura Y, Furukawa K, Morita K. Diabetic ketoacidosis associated with the pheochromocytoma of youth. Diabetes Res Clin Pract. 1996;34: $57-60$.

Ready to submit your research? Choose BMC and benefit from:

- fast, convenient online submission

- thorough peer review by experienced researchers in your field

- rapid publication on acceptance

- support for research data, including large and complex data types

- gold Open Access which fosters wider collaboration and increased citations

- maximum visibility for your research: over $100 \mathrm{M}$ website views per year

At BMC, research is always in progress.

Learn more biomedcentral.com/submissions 